\title{
CONHECIMENTO INTUITIVO E CONHECIMENTO ABSTRATO NA FILOSOFIA DE SCHOPENHAUER
}

\section{JOSÉ CLÉRISON SANTOS ALVES ${ }^{1}$}

RESUMO: O presente artigo pretender mostrar que no interior de $O$ mundo como vontade $e$ representação Schopenhauer nos apresenta uma distinção entre dois tipos de conhecimento, a saber: o intuitivo e o abstrato. $\mathrm{O}$ primeiro é um produto do entendimento unido às formas puras do espaço e do tempo: as representações intuitivas. O segundo é uma obra da faculdade de razão: as representações abstratas. Para Schopenhauer, a única função da razão é atuar como uma faculdade produtora de conceitos abstratos. Aqui, todos os conceitos da razão devem ter como referência o conhecimento intuitivo, pois, sem essa referência, a razão se perde em conceitos vazios de conteúdo.

PALAVRAS-CHAVE: Conhecimento; Linguagem; Entendimento; Razão; Vontade.

ABSTRACT: The present article intends to show that within The world as will and representation Schopenhauer presents a distinction between two types of knowledge, namely: the intuitive and the abstract. The first is a product of understanding united to the pure forms of space and time: intuitive representations. The second is a work of the faculty of reason: the abstract representations. For Schopenhauer, the only function of reason is to act as a faculty producing abstract concepts. Here, all the concepts of reason must have as reference intuitive knowledge, for without this reference reason is lost in empty concepts of content.

KEYWORDS: Knowledge; Language; Understanding; Reason; Will.

\section{1 - Introdução}

Schopenhauer elabora dois pontos de vista com relação ao mundo, a saber: o mundo como (als) representação e o mundo como (als) Vontade. Sob o ponto de vista da representação, o mundo possui um caráter meramente relativo às formas e modos subjetivos de representar. Diante disso, é possível notar a existência de uma espécie de estrutura subjetiva a priori, que dá ao sujeito a capacidade de produzir, pela representação, a dimensão fenomênica da realidade. O intelecto é preparado de tal forma que não torna o sujeito apto a perceber o "em-si" das coisas. Para Schopenhauer, essa mesma verdade é expressa de outra maneira pelos vedas ${ }^{2}$ e puranas $^{3}$ quando falam da doutrina de Maia:

Trata-se do véu de MAIA, o véu da ilusão, que envolve os olhos dos mortais, deixando-lhes ver um mundo do qual não se pode falar que é nem que não é, pois

\footnotetext{
${ }^{1}$ Professor de Filosofia do Instituto Federal de Educação, Ciência e Tecnologia Baiano (IF BAIANO). Mestre em Filosofia pela Universidade Federal da Bahia (UFBA). E-mail: clerison.alves@ifbaiano.edu.br.

${ }^{2}$ Os vedas formam a base do extenso sistema de escrituras sagradas do pensamento hindu.

${ }^{3}$ Os puranas são antigos textos do hinduísmo que elogiam várias divindades.
} 
assemelha-se ao sonho, ou ao reflexo do sol sobre a areia tomado a distância pelo andarilho como água, ou ao pedaço de corda no chão que ele toma como uma serpente. (Tais comparações são encontradas, repetidas, em inumeráveis passagens dos Vedas e dos Puranas.) $\mathrm{O}$ que todos pensam e dizem, entretanto, não passa daquilo que nós também agora consideramos, ou seja: o mundo como representação submetido ao princípio de razão suficiente. (SCHOPENHAUER, 2005, p. 49)

O véu de Maia é internamente ligado ao princípio de razão suficiente (Satz vom zureichenden Grunde). Representa o mundo visível, uma dimensão onírica que é pura aparência inconstante e inessencial. Maia é um véu que envolve a consciência humana. Aqui, o verdadeiro e o falso se confundem. E é nesse sentido que Schopenhauer inaugura a sua obra magna, O mundo como vontade e representação, dizendo: “O mundo é minha representação". (SCHOPENHAUER, 2005, p. 43). De acordo com o filósofo, o mundo é apenas representação que o sujeito cognoscente faz dele, ou seja, ele é apenas um objeto para este. Com efeito, a existência desse mundo depende essencialmente da consciência de um sujeito. Isto se verifica nas palavras do próprio autor:

Verdade alguma é, portanto, mais certa, mais independente de todas as outras e menos necessitada de uma prova do que esta: o que existe para o conhecimento, portanto o mundo inteiro, é tão-somente objeto em relação ao sujeito, intuição de quem intui, numa palavra, representação. (SCHOPENHAUER, 2005, p. 43).

Pressupondo que o mundo como representação depende essencialmente da consciência de um sujeito cognoscente, Schopenhauer concebe toda realidade, por parte do sujeito, como fruto de toda uma construção representativa. Com isso, o filósofo ressalta que toda essa realidade dada ao sujeito, de forma imediata, não mostra as coisas como deveriam ser em si mesmas. E o que é apreendido se resume a meras representações das próprias coisas. $\mathrm{O}$ mundo como representação depende, necessariamente, da relação entre sujeito e objeto, na medida em que estes são termos correlatos.

O mundo, considerado como representação [...] compreende duas metades inseparáveis. A primeira é o objeto que tem por forma o espaço e o tempo, e, por conseguinte, a pluralidade; a segunda é o sujeito que escapa à dupla lei do tempo e do espaço, sendo sempre o uno e indivisível em cada ser que percebe. Segue-se que, um único sujeito, mais o objeto, chegariam para constituir o mundo considerado como representação, tão completamente como os milhões de sujeitos que existem; mas, se este único sujeito que percebe desaparecer, ao mesmo tempo, o mundo concebido como representação desaparece também. (SCHOPENHAUER, 1958, p. 11).

Essa passagem mostra que Schopenhauer concentra sua reflexão na união inseparável entre sujeito e objeto. Toda experiência pressupõe a ação apriorística do tempo, do espaço e da causalidade. A divisão entre sujeito e objeto é a forma comum de todas as classes de representações concernentes ao princípio de razão suficiente. Somente a partir dessa divisão, torna-se possível pensar qualquer tipo de representação, abstrata ou intuitiva, pura ou 
empírica (Cf. SCHOPENHAUER, 2005, p. 43). Schopenhauer estabelece uma diferença capital entre todas as nossas representações. Para ele, as representações se nos apresentam como intuitivas e abstratas. As últimas correspondem a uma classe de representações: os conceitos - eles são uma propriedade exclusiva do ser humano, "cuja capacidade para formulá-los o distingue dos animais" (SCHOPENHAUER, 2005, p. 47). Essa capacidade de formular conceitos é denominada razão. Mas, para formular os conceitos, a razão precisa extrair seu material das representações intuitivas. Neste momento, nos dedicaremos a tratar destas representações, pois elas correspondem à base de todo edifício sobre o qual assenta o conhecimento abstrato produzido pela razão discursiva.

\section{2 - O conhecimento intuitivo}

A representação intuitiva concerne a todo mundo visível - é imediata e autossuficiente. Além disso, essa classe de representações abrange toda experiência possível; todas as condições de possibilidade de conhecimento residem nela. Para Schopenhauer, a intuição não é um fantasma extraído por meio da repetição da experiência, ao contrário, a experiência sempre deve ser pensada como dependente dela (Cf. SCHOPENHAUER, 2005, p. 47). As formas do espaço e do tempo são conhecidas a priori pela intuição. Toda experiência possível obedece a essas formas subjetivas do espaço e do tempo - são formas universais da intuição, "são intuíveis por si, independentes da experiência" (SCHOPENHAUER, 2005, p. 48).

O tempo puramente intuído é forma mais simples do princípio de razão suficiente, toda numeração e todo cálculo são baseados nele. A sucessão constitui-se como a forma do princípio de razão no tempo - a essência do tempo é a sucessão. O espaço puramente intuído diz respeito à propriedade das partes da extensão se determinarem reciprocamente - a essência do espaço é a posição. A união operada pela causalidade entre tempo e espaço corresponde à essência da matéria. Aqui, matéria é o fazer-efeito estabelecido pela lei de causalidade. Quando o entendimento aplica a lei de causalidade nas formas puras do tempo e do espaço, surgem as representações intuitivas.

Em Kant, o entendimento, por meio dos conceitos puros, age no campo do conhecimento abstrato, ou seja, ele não intui. No entanto, em Schopenhauer, o entendimento intui empiricamente, isto é, ele age no campo do conhecimento intuitivo. Na perspectiva do autor de $O$ Mundo, o entendimento, através da lei de causalidade aplicada às formas puras do espaço e do tempo, fornece o material para que sejam produzidos os conceitos abstratos da 
razão. Sem essa síntese, operada pelo entendimento, é impossível desenvolver o conhecimento abstrato ${ }^{4}$. Em suma, o filósofo distingue o tipo de conhecimento produzido pelo entendimento do tipo de conhecimento produzido pela razão. É nesse aspecto que Schopenhauer afirma que muitos filósofos se confundiram em relação a esses dois conceitos distintos:

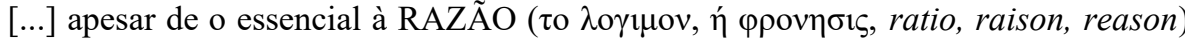
ter sido corretamente conhecido, no todo e em geral, por todos os filósofos nas diversas épocas - embora não definido de maneira suficientemente precisa e remetido a um único ponto - por outro lado, não lhes era claro o que

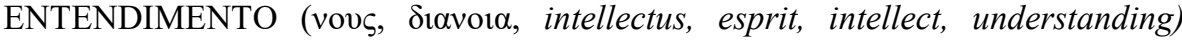
significava. Daí o terem com frequência confundido com a razão, e, por isto mesmo, não alcançaram uma definição completa pura e simples de sua natureza. (SCHOPENHAUER, 2005, p. 648).

Com essa distinção, Schopenhauer mostra que o entendimento - conhecedor da lei de causalidade - é anterior à razão discursiva. Em síntese, o mundo como representação é caracterizado pela atuação causal do entendimento. Ademais, sem essa operação do entendimento, o mundo como representação não seria possível. O filósofo afirma:

[...] o entendimento, antes de tudo, torna a intuição possível, pois apenas dele se origina a lei de causalidade, a possibilidade de causa e efeito, que também vale apenas para ele; em consequência, apenas para e mediante ele existe o mundo intuitivo. (SCHOPENHAUER, 2005, p. 63).

É importante ressaltar que o entendimento é completamente alheio à razão. Neste sentido, o tipo de conhecimento produzido pelo entendimento é essencialmente diferente do tipo de conhecimento produzido pela razão discursiva. $O$ filósofo sustenta que os seres humanos compartilham a mesma dimensão intuitiva do conhecimento com os animais, ou seja, os animais também possuem o entendimento. Com efeito, do ponto de vista da forma, o mesmo entendimento que atua no homem, atua também no animal. Schopenhauer ressalta: "O entendimento é o mesmo em todos os animais e homens, possui sempre e em toda parte a mesma forma simples: o conhecimento da causalidade, passagem do efeito à causa e desta ao efeito, e nada mais" (SCHOPENHAUER, 2005, p. 64).

Para o autor de $O$ Mundo, a carência de entendimento pode ser chamada de estupidez, que significa: “OBTUSIDADE NO USO DA LEI DE CAUSALIDADE, incapacidade para a concepção imediata da concatenação de causa e efeito, de motivo e ação" (SCHOPENHAUER, 2005, p. 66). Segundo Schopenhauer, um homem obtuso não consegue reconhecer a concatenação dos fenômenos naturais onde eles aparecem espontaneamente,

\footnotetext{
${ }^{4}$ De modo diferente do de Kant, o ponto de partida da filosofia de Schopenhauer é o conhecimento intuitivo e imediato. Sendo este a fonte de toda evidência, segundo Schopenhauer, a filosofia precisa partir dele para atingir o conhecimento abstrato.
} 
nem mesmo quando são eles produzidos mecanicamente - "por isso acredita candidamente em magias e milagres" (SCHOPENHAUER, 2005, p. 66). O espírito obtuso não consegue perceber que várias pessoas, aparentemente isoladas umas das outras, podem perpetrar uma ação conjuntamente. Por esse motivo, ele se deixa enganar, pois não consegue perceber as motivações secretas oriundas dos conselhos que foram recebidos de outrem, ou dos juízos que lhe são dirigidos. "Sempre lhe falta apenas uma coisa: argúcia espiritual, rapidez, facilidade no uso da lei de causalidade, isto é, faculdade de entendimento" (SCHOPENHAUER, 2005, p. 66). No livro I de $O$ Mundo, Schopenhauer nos apresenta um exemplo interessante de estupidez:

O caso mais significativo, e, nesse aspecto considerado, bastante instrutivo de obtusidade que conheci foi de um rapaz no todo imbecil, com cerca de onze anos internado em um manicômio, que até possuía razão, pois falava e compreendia, mas em termos de entendimento se situava abaixo dos animais. Todas as vezes que chegava, ele se detinha na consideração de duma lente de óculos que trazia pendurada no pescoço e na qual apareciam refletidas a janela do quarto e a copa das árvores atrás dela. Todas as vezes, ele sempre era assaltado de grande admiração e alegria, nunca se cansando de observá-lo com espanto, visto que não entendia a causalidade completamente imediata do reflexo da luz. (SCHOPENHAUER, 2005, p. 66).

Conforme Schopenhauer, os graus de agudeza do entendimento são muito variados tanto nos homens quanto nos animais. Porém, nos animais esses graus de agudeza são mais variados ainda. Nos animais considerados mais inteligentes, o entendimento atua acima das expectativas, operando em toda sua potencialidade - sem o uso da razão. Como no surpreendente exemplo dado pelo filósofo:

[...] nos surpreende a sagacidade daquele elefante que, após ter atravessado várias pontes em sua jornada pela Europa, recusou-se certa vez a entrar numa, sobre a qual viu o cortejo de homens e cavalos, porque ela the parecia levemente construída para o seu peso. (SCHOPENHAUER, 2005, p. 67).

Diante desse exemplo, fica evidente que o conhecimento de causa e feito, produzido pelo entendimento, se nos apresenta como completamente independente do conhecimento abstrato produzido pela razão discursiva. A finalidade do entendimento é unir o efeito à causa. Ademais, a lei de causalidade é a condição prévia da representação. A operação realizada pelo entendimento não é discursiva nem reflexiva, mas sim direta e imediata.

A realidade tem como seu contrário a aparência - ilusão produzida pelo entendimento. No que se refere à questão da aparência, o entendimento fica destituído de critérios para distinguir o efeito da causa. Neste sentido, o entendimento forja uma causa fictícia como um objeto da intuição - essa é a natureza da aparência. Schopenhauer sustenta que a razão consegue eliminar a ilusão, mas, não consegue destruí-la - o intelecto é puro e 
irracional. Em Sobre a visão e as cores (1815), um tratado escrito pelo jovem Schopenhauer, já podemos encontrar essa tese:

[...] numa tal ilusão promovida intencionalmente sabemos muito bem in abstracto, ou seja, para a razão, que, por exemplo, só existe um objeto, embora com olhos vesgos e dedos cruzados vemos e tocamos dois, ou que existem dois, embora vemos apenas um; mas apesar desse conhecimento abstrato a própria ilusão mantém-se intacta, pois o intelecto e a sensibilidade são inacessíveis para os princípios de razão, isto é, são irracionais. Disso resulta também o que na realidade seriam aparência e o equívoco: aquela, o engano do intelecto e este, o engano da razão; aquela, contrária à realidade e este, à verdade. (SCHOPENHAUER, 2003, p. 40-41).

A partir disso, vemos que a aparência concerne ao intelecto e o equívoco se refere à razão; a aparência nasce quando do estado incomum (diferente do estado em que a razão aprendeu a utilizar a sua função) dos órgãos dos sentidos "submete-se à apreensão sempre regular e imutável da razão; ou quando o efeito recebido pelos sentidos todo dia e toda hora em função de uma única causa seja de repente produzida por uma outra causa" (SCHOPENHAUER, 2003, p. 40-41). Por exemplo: quando um pedaço de madeira é colocado dentro da água, automaticamente ele irá apresentar-se aos olhos de um determinado indivíduo de modo disforme - o conhecimento intelectual é puro e irracional - mas, pela faculdade de razão, este indivíduo, já no campo dos conceitos abstratos e de suas relações recíprocas, não se prenderá mais à ilusão intuitiva; o equívoco surge a partir de um julgamento da razão. Em relação ao exemplo dado acima, se o indivíduo afirma: "vejo um pedaço de madeira partido dentro da água", seria correto do ponto de vista dos sentidos. Podese eliminar o equívoco através do julgamento verdadeiro, sem deixar de levar em consideração a aparência como causa. Todavia, não é possível eliminar a aparência, nem mesmo através do conhecimento racional abstrato (Cf. SCHOPENHAUER, 2003, p. 42).

Não podemos deixar de levar em consideração que o sujeito só pode formar as representações intuitivas porque possui um corpo. É através do corpo que o sujeito do conhecimento enraíza-se no mundo. As afecções produzidas pelo corpo unem o sujeito ao mundo, fazendo com que ele passe a intui-lo por meio do entendimento. Do que foi exposto até aqui, temos como resultado o conhecimento intuitivo como produto da ação do entendimento vinculado às formas puras do espaço e do tempo. $\mathrm{O}$ conhecimento intuitivo é o fundamento de todo conhecimento abstrato. Em síntese, a razão só pode produzir os conceitos abstratos a partir das intuições empíricas fornecidas pelo entendimento.

Enquanto permanecermos intuindo através do entendimento, a verdade e o erro não nos ocuparão, pois não existe erro no campo do conhecimento intuitivo. Na caverna platônica, os prisioneiros só caem no erro quando falam das sombras que veem desfilar. Para 
Schopenhauer, não existe erro no plano da intuição. A verdade do entendimento é a verdade ingênua do olhar, para o qual até mesmo as ilusões dos sentidos se mostram como verdadeiras em sua imediatez. O erro só entra em cena no campo do conhecimento abstrato.

\title{
3 - O conhecimento abstrato
}

Todo conhecimento - intuitivo e abstrato - estriba-se na operação realizada pelo entendimento por meio da lei de causalidade. Pois, somente desta maneira, podemos obter as representações. Schopenhauer conclui sua dissertação de doutorado - Sobre a quádrupla raiz do princípio de razão suficiente - com o objetivo de valorizar o conhecimento intuitivo e imediato em oposição à representação abstrata. Para o filósofo, a intuição corresponde à imagem de um solo firme e seguro. Embora $O$ Mundo tenha sido escrito depois da Quádrupla, a seguinte passagem serve para ilustrar essa tese:

\begin{abstract}
Como da luz imediata do sol à luz emprestada e refletida da lua, passaremos agora da representação intuitiva, imediata, auto-suficiente e que se garante a si mesma, à reflexão, isto é, aos conceitos abstratos e discursivos da razão, que têm seu conteúdo apenas a partir e em referência ao conhecimento intuitivo. Durante o tempo que nos mantemos intuindo de modo puro, tudo é claro, firme, certo. Inexistem perguntas, dúvidas, erros. Não se quer ir além, não se pode ir além; sentimos calma no intuir, satisfação no presente. A intuição se basta a si mesma. (SCHOPENHAUER, 2005, p. 81).
\end{abstract}

É no campo do conhecimento abstrato, segundo Schopenhauer, que a dúvida e o erro entram em cena. Aqui, o erro e a dúvida só começam com a razão e as representações abstratas que, ligadas à linguagem, tentam reconstruir precariamente o mundo das representações intuitivas. Schopenhauer ilustra essa percepção: “[...] junto com o conhecimento abstrato, com a razão, dúvida e erro entram em cena no domínio teórico, cuidado e remorso no prático" (SCHOPENHAUER, 2005, p. 81). Na representação intuitiva, a ilusão distorce momentaneamente a realidade. Contudo, na representação abstrata o erro pode atravessar vários séculos, e com isso impor "seu julgo férreo a povos inteiros, sufocando as mais nobres disposições, e, mesmo quem não é por ele enganado, é acorrentado por seus escravos ludibriados" (SCHOPENHAUER, 2005, p. 81).

Partindo das sólidas bases da filosofia kantiana, Schopenhauer introduz a maior parte dos elementos da Estética Transcendental dentro do seu sistema. Mas, por outro lado, ele também realiza uma profunda transformação no que concerne às características importantes do pensamento kantiano ${ }^{5}$. Enquanto Kant pensa a sensibilidade como produtora de intuições,

\footnotetext{
5 A partir da $2^{\mathrm{a}}$ edição de $O$ Mundo (1844), Schopenhauer faz as doutrinas kantianas passarem por uma transformação fisiológica, pois ele, com muita tranquilidade, consegue se referir ás formas da inteligência como funções do cérebro. O filósofo considera o entendimento (Verstand), para ele (Intellekt), como o cérebro
} 
o entendimento como produtor de conceitos puros e a razão como produtora de ideias, Schopenhauer sustenta, distanciando-se do seu mestre, que a sensibilidade unida ao entendimento produz as representações intuitivas; já a razão, por sua vez, produz as representações abstratas. Diferentemente de Kant, que toma o entendimento como fonte dos conceitos, Schopenhauer afirma que o entendimento não é responsável por gerar conceitos, já que, para ele, a razão assume este tipo específico de tarefa.

O entendimento possui uma única função, o conhecimento imediato da lei de causalidade - a intuição imediata do mundo efetivo. Assim como o entendimento, a razão também possui uma única função, a saber: a tarefa de produzir os conceitos abstratos (SCHOPENHAUER, 2005, p. 85). Os conceitos possuem a função de representações simplificadoras, ou seja, eles realizam uma espécie de abreviação das representações intuitivas, pois acabam extraindo delas aquilo que, de certa forma, pode ser considerado como o mais essencial. Os conceitos procuram apenas reduzir o excesso de uma suposta carga intuitiva, para assim ficar com o que é necessário e eliminar todo o resto como acessório. Segundo o filósofo, temos nos conceitos a retenção daquilo que não pode ser percebido de forma isolada, pois eles são "extratos", já que estes diferem das representações intuitivas, embora sejam oriundos delas.

O filósofo reconhece a singularidade da razão por ser uma função única no que tange à elaboração dos conceitos. Porém, antes de tudo, ele procura distingui-la do entendimento que tem como função a viabilização do conhecimento da relação entre causa e efeito (SCHOPENHAUER, 2005, p. 85). Com isso, Schopenhauer afirma que os conceitos abstratos não trazem a certeza da intuitividade, pois mesmo que a razão identifique o erro, ela não poderá corrigi-lo, ou seja, a faculdade da razão não tem o poder de transformar a representação. Assim, sustenta Schopenhauer:

[...] ilusões enganadoras se posicionam como intuições imediatas diante de nós, impossíveis de serem eliminadas pelo razoamento. Este pode prevenir o erro - isto é, o juízo sem fundamento suficiente - apenas mediante um juízo oposto e verdadeiro, permitindo conhecer in abstracto que a causa do brilho mais fraco da lua e das estrelas não é a distância maior, mas o ar mais denso no horizonte. (SCHOPENHAUER, 2005, p. 69).

Schopenhauer nos adverte contra a faculdade de razão, uma vez que a filosofia e a ciência depositam nela uma excessiva confiança. A filosofia e a ciência "a encarregam de

(Gerhirn). Além disso, depois do contato com a doutrina platônica e com a doutrina vedanta, Schopenhauer passa a considerar o fenômeno (Erscheinung) como aparência (Schein). Com isso, a representação resume-se apenas a um encanto ("Zauber"), um sonho ("Traum”), um véu ("Schleier”). A coisa-em-si da filosofia de Kant - o limite externo do conhecimento - na filosofia de Schopenhauer passa a ser algo de que temos notícia imediata a partir do sentimento do corpo. Essa identificação da coisa-em-si com a vontade terá grandes implicações na ética schopenhaueriana, e, além disso, será um ponto de distanciamento entre os dois pensadores. 
garantir a certeza, a verdade e a felicidade" (PERNIN, 1995, p. 63). Confiantes na razão, os homens não hesitam em incumbi-la de todas as tarefas que não lhe cabem, em estender sobre todas as coisas a sua jurisdição; teoricamente, sobrecarregam a razão com todas as formas do princípio de razão suficiente, ao passo que ela rege apenas uma delas. Os homens têm confiança na razão. Herdeiro do romantismo ${ }^{6}$, Schopenhauer pretende abalar essa confiança. Assim, sustenta o filósofo: "o erro é o inimigo contra o qual os mais sábios espíritos de todos os tempos travaram uma batalha desigual e apenas o que nela conquistaram se tornou patrimônio da humanidade" (SCHOPENHAUER, 2005, p. 81).

Schopenhauer é um crítico da razão como critério de dominação do mundo. Para ele, a razão é faculdade que distingue indiscutivelmente o homem do animal. Nos animais irracionais, a inocência e a transparência caracterizam todas as suas ações. Contudo, no homem, essa visibilidade, no que concerne às ações, fica comprometida; a transparência e a inocência do animal não existem nele. Através da faculdade de razão, o homem pode calcular antecipadamente as grandes linhas de sua conduta futura, seguindo um plano combinado e preparado, eventualmente secreto, e prever consequências dos seus atos e dos atos dos outros (SCHOPENHAUER, 2005, p. 83).

A visão de Schopenhauer em relação ao conhecimento abstrato anuncia a sua concepção da destinação utilitária da inteligência e, por conseguinte, enfraquece as pretensões racionalistas. De acordo com o filósofo, a razão não é faculdade das ideias. Em outras palavras, ela não pode nos dar um conhecimento Absoluto. Aqui, os conceitos mais elevados correspondem aos mais pobres, pois cada grau de abstração é motivo de perda de riqueza intuitiva. A abstração do conceito, que mantém apenas o essencial, é a condição da sua generalidade, quer dizer, da sua extensão. Nesta medida, a extensão do conceito é, pois, uma propriedade secundária, que não o define como tal. A lógica é a teoria das relações de extensão dos conceitos. Ela corresponde ao princípio de razão suficiente do conhecimento - a ratio cognoscendi. Essa forma do princípio sustenta que toda representação abstrata tem como essência a relação que existe entre ela e outra representação. Do mesmo modo, as representações remetem incessantemente umas às outras. Contudo, Schopenhauer insiste no fato de que esse jogo de remissão conceitual deve ter um limite:

[...] segue-se que a representação abstrata possui sua essência, inteira e exclusivamente, em sua relação com uma outra representação que é seu fundamento

\footnotetext{
${ }^{6}$ Schopenhauer viveu nos séculos XVIII e XIX. Nesse sentido, ele acompanhou as transformações culturais que atravessaram a Europa. O Iluminismo acentuou o primado da razão em relação aos sentidos e o Romantismo priorizou os sentimentos em relação à razão. Esses movimentos foram determinantes para que o filósofo pudesse desenvolver o seu pensamento, tornando a sua obra magna $O$ mundo como vontade e representação uma das maiores expressões do pensamento romântico alemão.
} 
de conhecimento. Esta última pode ser de novo um conceito, ou representação abstrata, que por sua vez também pode ter um semelhante fundamento de conhecimento; mas não ao infinito, pois a série de fundamentos de conhecimento tem de findar num conceito que tem seu fundamento no conhecimento intuitivo. Em verdade, o mundo todo da reflexão estriba sobre o mundo intuitivo como seu fundamento de conhecer. (SCHOPENHAUER, 2005, p. 88).

A faculdade de razão não poderia realizar o processo de abstração sem a linguagem, como sugere a palavra grega logos, que as reúne. "Por isso, em grego e italiano, linguagem e

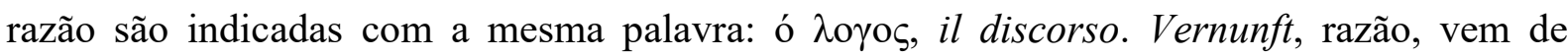
Vernehmen, inteligir, que não é sinônimo de Hören, ouvir, mas significa a conscientização de pensamentos comunicados por palavras" (SCHOPENHAUER, 2005, p. 83). Na perspectiva de Schopenhauer, não existe intuição racional, já que, por natureza, a razão é discursiva - ela precisa da linguagem. Por meio da linguagem, a razão consegue obter grandes realizações. Não obstante, a linguagem também permite a propagação do erro. Schopenhauer assevera:

\begin{abstract}
Somente com a ajuda da linguagem a razão traz a bom termo suas mais importantes realizações, como ação concordante de muitos indivíduos, a cooperação planejada de muitos milhares de pessoas, a civilização, o Estado, sem contar com a ciência, a manutenção de experiências anteriores, a visão sumária do que é comum num conceito, a comunicação da verdade, a propagação do erro, o pensamento e a ficção, os dogmas e as superstições. (SCHOPENHAUER, 2005, p. 83-84).
\end{abstract}

No capítulo 6 dos Suplementos ao Mundo, Schopenhauer sustenta que os conceitos abstratos da razão, mesmo não sendo idênticos às palavras, são representações cuja consciência clara e conservação liga-se de modo necessário à palavra. As palavras fixam os conceitos, que a pouca durabilidade da consciência, que acompanha o fio do tempo, deixaria escapar, visto que eles não dizem respeito mais a uma intuição. Assim, é comunicada a experiência, tornando possível a tradição. Em contrapartida, a intuição é incomunicável:

Se as intuições fossem comunicáveis, seria, então, uma comunicação que valesse a pena, mas no final cada um permanece dentro de sua própria pele e do seu próprio crânio, sem poder ajudar um ao outro. (SCHOPENHAUER, 1958, p. 74).

É impossível comunicar a intuição. Nesta medida, a razão só produz representações das representações, ela não intui. "Os conceitos permitem apenas pensar, não intuir, e tão somente os efeitos que o homem produz por eles são objetos da experiência propriamente dita" (SCHOPENHAUER, 2005, p. 89). Por outro lado, as representações abstratas são eminentemente comunicáveis. Segundo Schopenhauer, compreendemos a linguagem dos outros graças às representações abstratas e não graças às imagens. A razão é dada a todos. Schopenhauer enfatiza a inutilidade das regras da lógica que todos possuem, a partir do momento que têm acesso à linguagem. Entretanto, o jogo estabelecido pelas representações abstratas corresponde a uma perda significativa no que se refere à manutenção do material 
fornecido pela intuição. Neste sentido, é possível notar que o mundo das representações abstratas mutila o mundo das representações intuitivas. Em outras palavras, é uma tradução de tradução.

As representações abstratas são representações de representações. Por esse motivo, elas se apresentam, para Schopenhauer, como qualitativamente empobrecidas. Além disso, as representações abstratas se multiplicam e entram num processo frenético de circulação, cujas formas desiguais são a opinião pública, os boatos e a leitura. Conforme a metáfora schopenhaueriana, essa circulação de bilhetes não obedece à soma exata do dinheiro efetivo depositado nos caixas: as intuições seriam o dinheiro efetivo, e os conceitos seriam os bilhetes. Aqui, a razão vive segundo o regime da inflação crônica.

Em Schopenhauer, a maior fonte do erro é a multiplicidade dos conceitos intermediários. O filósofo sustenta que a procura indiscriminada pelas causas, através do método indutivo, é responsável por muitos erros. Ademais, o percurso lógico também é criticado por ele. Diante de conceitos mal determinados e vagos, um indivíduo que exerce a arte de persuadir termina por encontrar um terreno favorável, de tal modo que pode muito bem utilizar os conceitos a partir da finalidade visada, e, ainda, encadeá-los através de uma análise superficial de suas relações, a fim de chegar à finalidade a que se propõe. ${ }^{7}$ No livro I de $O$ Mundo, Schopenhauer nos dá um exemplo através do conceito de viagem.

Do ponto de vista schopenhaueriano, as muitas opiniões, que correspondem às representações abstratas, tornar-se-ão motivos determinantes no que tange às ações humanas, o que poderá justificar algumas condutas absurdas, loucas ou criminosas adotadas pelos homens. Segundo ele, os erros da razão são nefastos. Como um crítico ferrenho da concepção de razão que não leva em consideração o conhecimento intuitivo, o filósofo sustenta que ela pode contribuir para desorientar os homens, uma vez que estes podem utilizá-la tanto para o bem, quanto para o mal.

Schopenhauer considera perigosa a passagem da intuição para o conceito. Para o filósofo, este é o lugar onde o erro é retransmitido, a pedra em que tropeçam as inteligências desatentas. Desta forma, ele ressalta que o exercício da razão nos concede a possibilidade de deduzir consequências, provar e concluir; e que isso é dado ao indivíduo cuja razão é sã. No entanto, julgar é uma operação muito mais complexa. Schopenhauer evidencia deste modo:

\footnotetext{
${ }^{7}$ Para aprofundar essa temática, ver SCHOPENHAUER, Como vencer um debate sem precisar ter razão em 38 estratagemas (Dialética Erística), 2003. Nesta obra, Schopenhauer realiza uma análise de alguns esquemas argumentativos enganosos que são normalmente utilizados para enganar o público desavisado. Segundo o filósofo, para que um sistema filosófico possa ser considerado consistente é necessário romper, preliminarmente, com todos os argumentos falaciosos.
} 
[...] deduzir proposições de proposições, demonstrar, concluir, é algo acessível a todos, desde que possua a razão saudável. Ao contrário, recolher e fixar o que foi conhecido intuitivamente em conceitos apropriados para a reflexão, de tal modo que, de um lado, aquilo comum a muitos objetos reais seja pensado por UM conceito e, de outro, o diferente deles seja pensado por outros tantos conceitos, e, assim, o diferente, apesar de uma concordância parcial, seja pensado e conhecido como diferente, e o idêntico, apesar de uma diferença parcial, seja pensado e conhecido como idêntico, conforme o fim e o aspecto que convenha a cada caso: eis em tudo isso uma tarefa da FACULDADE DE JUÍZO. (SCHOPENHAUER, 2005, p. 116).

De acordo com Schopenhauer, as representações abstratas terminam por tornar as decisões mais complexas e a hesitação frequente, já que o homem se vê dominado, simultaneamente, por motivos intuitivos imediatos e por motivos oriundos das representações abstratas. Com isso, o processo de reflexão se torna pouco seguro, mesmo que os efeitos de sua ação coletiva sejam mais poderosos. Para o filósofo, o bom julgamento é extremamente raro, uma vez que ele se nos apresenta como reservado a alguns eleitos. Desta maneira, os homens, em sua maior parte, não julgam por si mesmos, mas abandonam-se aos preconceitos conduzidos pelos conceitos, que, por sua vez, estão depositados na linguagem.

Na Quádrupla, Schopenhauer apresenta a base da sua teoria da linguagem unida à sua concepção acerca da forma lógica do juízo. Nessa teoria, o filósofo mostra que a combinação de conceitos, no que concerne à expressão linguística, recebe o nome de juízo. Além disso, os conceitos constituem os elementos primários do juízo. Para dizer o mundo, temos que observar os diferentes níveis de ajuizamento, aos quais dizem respeito a diferentes níveis de realidade. Isso indica que existem diferentes perspectivas que envolvem a noção de verdade no que diz respeito à construção de um juízo. Como se sabe, no campo do conhecimento intuitivo, temos a verdade ingênua do olhar. $\mathrm{O}$ entendimento não precisa da linguagem. Por esse motivo, a sua verdade é de outra ordem - todas as ilusões produzidas pelos sentidos são, em sua imediatez, verdadeiras - como no caso de uma miragem. Contudo, quando os conceitos passam a ocupar a consciência, a ingenuidade desaparece. É importante ressaltar que a ilusão não é suprimida. O que desaparece, de fato, é a ingenuidade do sujeito do conhecimento. Como vimos anteriormente, a razão não tem o poder de corrigir a ilusão produzida pelo entendimento.

Com o surgimento da faculdade de razão, o entendimento passa a ser acompanhado. Em outras palavras, a razão tenta "substituir" a verdade ingênua do entendimento. A partir daí, é possível falar sobre verdade e erro no âmbito dos juízos. O domínio dos juízos é caracterizado pelo saber, o que equivale a se ter determinados juízos em poder do próprio espírito, com a finalidade de uma reprodução subsequente. O saber anseia pela verdade. Ora, o que vem a ser a verdade para Schopenhauer? 
A verdade é, portanto, a relação de um juízo com algo diferente dele, que se chama razão (Grund), e, como veremos, suporta uma variedade significativa de espécies. Mas, no entanto, como o juízo é sempre algo que se baseia ou se apoia, a palavra alemã Grund (fundamento) tem sido bem escolhida (SCHOPENHAUER, 1981, p. 158).

A partir disso podemos concluir que a verdade corresponde à relação de um juízo com algo exterior a ele - seu fundamento suficiente. Para o autor de $O$ Mundo, os fundamentos nos quais os juízos são tomados como verdadeiros aparecem distribuídos em quatro classes que, por sua vez, concernem a quatro tipos de verdade - quatro formas de expressar verdadeiramente a realidade por meio da linguagem.

$A$ verdade lógica. Um juízo pode ter por fundamento outro juízo. A verdade desse tipo de juízo é formal. A fundamentação de um juízo por outro nasce sempre de uma comparação com ele; é uma mera conversão ou contraposição dos mesmos - da relação dos juízos entre si nasce a verdade. Essa operação é chamada de silogismo. Acontece tanto por oposição como subsunção dos conceitos. Schopenhauer apresenta os seguintes exemplos: a) o juízo "um triângulo é um espaço encerrado por três linhas" é uma verdade que tem como último fundamento o princípio de identidade, isto é, o pensamento expresso a partir deste; b) o juízo "nenhum corpo é sem extensão" tem como último fundamento o princípio de contradição; c) o juízo "todo juízo é ou verdadeiro ou não verdadeiro" tem como último fundamento o princípio do terceiro excluído; d) o juízo "ninguém pode tomar algo como verdadeiro sem saber por que" tem como último fundamento o próprio princípio de razão de conhecer (Cf. SCHOPENHAUER, 1981, p. 160). Com isso, se pode afirmar que toda verdade lógica é extrínseca, ou seja, é a relação de um juízo com algo exterior a ele, de modo que a verdade intrínseca, que só se apoiaria nas leis do pensamento e não em outros juízos, é uma contradição nos termos.

$A$ verdade empírica. Uma representação da primeira classe, ou seja, uma intuição obtida por meio dos sentidos, e que é por isso experiência, pode ser fundamento de um juízo: então o juízo tem verdade material, caso em que ele se funda imediatamente na experiência - é verdade empírica. Dizer que um juízo tem verdade material significa em geral que seus conceitos estão ligados, separados, ou limitados entre si, implicando na exigência das representações intuitivas. Conhecer é obra imediata da faculdade de juízo (Urtheilskraft). A faculdade de juízo exerce o papel de mediador entre a faculdade de conhecimento intuitivo e a faculdade do conhecimento abstrato e discursivo, quer dizer, entre o entendimento e a razão (Cf. SCHOPENHAUER, 1981, p. 160). 
A verdade transcendental. As formas de conhecimento intuitivo empírico, residentes no entendimento e na sensibilidade pura (tempo, espaço e causalidade), podem ser condições de possibilidade de toda experiência, fundamento de um juízo, que é então um juízo sintético $a$ priori: são os conhecimentos matemáticos. Exemplos de tais juízos são proposições como as seguintes: "duas linhas retas não encerram espaço algum" (espaço); "3 x $7=21$ ” (tempo); "a matéria não nasce nem perece" (causalidade) (Cf. SCHOPENHAUER, 1981, p. 160).

$A$ verdade metalógica. Essa verdade concerne às condições formais de todo o pensar como o fundamento de um juízo. Conforme Schopenhauer, os juízos metalógicos correspondem a apenas quatro: a) "um sujeito é igual à soma de seus predicados ou $a=a$ "; b) "um predicado não pode ao mesmo tempo ser atribuído e retirado ao sujeito" ou "a- a =0"; c) "de dois predicados opostos e contraditórios um tem de convir ao sujeito"; d) "a verdade é a relação de um juízo com algo exterior a ele, que é o seu fundamento suficiente" (Cf. SCHOPENHAUER, 1981, p. 160). Aqui, a razão se "auto-investiga". É ela que conduz a reconhecer que todos esses quatro juízos são a fórmula das condições do pensar em geral.

Em Schopenhauer, a natureza da verdade - teoria do juízo - é extrínseca, e não intrínseca. Contudo, o único caso em que a verdade pode ser considerada como intrínseca é na condição da intuição empírica - representação submetida ao princípio de razão suficiente do devir. Aqui, temos a verdade ingênua do olhar, ou seja, uma ilusão produzida pelo entendimento em seu total estado de pureza. Por exemplo: uma miragem jamais poderá ser corrigida pela faculdade da razão, pois não se trata de uma verdade extrínseca, quer dizer, de um juízo que possua como fundamento algo que seja exterior a ele. Em suma, trata-se de um engano no âmbito dos sentidos.

Essas quatro formas específicas de verdade correspondem consequentemente a quatro dimensões da realidade. Nesta medida, temos uma espécie de perspectivismo em relação à noção de verdade (Cf. BARBOSA, 2005, p. 132). Com isso, não faz sentido utilizar uma verdade para corrigir outra, uma vez que cada verdade concerne a uma dimensão específica da realidade. Para Schopenhauer, a filosofia deve atuar na perspectiva de demarcar os níveis de atuação da razão discursiva. $O$ filósofo condena a linguagem excessivamente abstrata encontrada em alguns sistemas filosóficos. A filosofia constrói suas explicações sobre o mundo e as coisas a partir do domínio das verdades empíricas. Essas verdades são a referência exterior de toda linguagem empregada na filosofia. De acordo com o autor de $O$ Mundo, os conceitos devem sempre encontrar sua referência na intuição. Neste sentido, a intuição deve 
funcionar como um mecanismo regulador de todas as explicações oriundas da razão discursiva.

Segundo Schopenhauer, os conceitos mais distantes da intuição são os que menos dizem. Por exemplo: Deus, alma, substância, essência, infinito, perfeito. O filósofo ressalta que conceitos como esses não possuem uma referência intuitiva e, por causa disso, são vagos. Em síntese, quando deixamos de observar a importância do conhecimento intuitivo no que tange à construção do conhecimento abstrato, acabamos caindo no erro. Segundo o filósofo, todo conhecimento abstrato repousa terminantemente no conhecimento intuitivo. É o entendimento unido às formas a priori da sensibilidade que dita as regras do jogo. Logo, todo saber abstrato encontra sua referência na dimensão intuitiva do conhecimento.

A teoria schopenhaueriana do juízo e da linguagem apresenta os níveis de expressão da razão discursiva. Com isso, o filósofo prepara o caminho para demonstrar que o princípio de todas as coisas não é racional e inteligível, mas antes algo de irracional e sem-fundamento (Grundlos). Algo que a razão discursiva não consegue alcançar por meio dos conceitos e da linguagem. Aqui, o real oculta-se por meio do princípio de razão suficiente. No ponto de vista schopenhaueriano, a razão resume-se apenas em expressar a verdade da finitude, isto é, às aparências temporais. O filósofo chega à conclusão de que o princípio de razão suficiente não nos permite ultrapassar o limite da experiência, como também não nos permite decifrar o enigma desta. $\mathrm{O}$ entendimento nos possibilita a experiência, mas, ao mesmo tempo, impõe um limite intransponível no que concerne às explicações oriundas da razão discursiva. Os conceitos e a linguagem devem obedecer ao limite da experiência sensível, uma vez que não podemos ir além dela.

\section{4 - A relação entre o intuitivo e o abstrato}

De acordo com Schopenhauer, todos os conceitos recebem seu material do conhecimento intuitivo. Por isso, todo edifício do nosso pensamento estriba no mundo das intuições. O filósofo denomina as intuições de representações primárias e os conceitos de representações secundárias. Para ele, a maior parte do filosofar consiste em explicar palavras com palavras, comparar conceitos com conceitos. Isso corresponde a uma espécie de jogo entre as esferas conceituais com a finalidade de ver qual delas se encaixa numa outra e não na outra. Esse jogo entre as esferas conceituais (o raciocínio) não acrescenta nada de novo ao conhecimento, pois se resume a mostrar o que já está contido no conhecimento existente. Em contrapartida, o ato de intuir nos impulsiona a deixar que as coisas falem por si mesmas, 
apreendendo as novas relações entre elas, depositando tudo isso em conceitos, para que, assim, eles possam ser utilizados com segurança - isso gera novos conhecimentos.

Segundo o autor de $O$ Mundo, quase todos possuem a capacidade de comparar conceitos com conceitos. Mas comparar conceitos com intuições é algo para poucos. Somente os homens de gênio possuem esse dom. No capítulo 7 dos Suplementos ao Mundo, é possível notar, com muita clareza, a importância que Schopenhauer deposita na dimensão intuitiva do conhecimento. O núcleo íntimo de todo conhecimento reside na intuição e, por conseguinte, cada nova verdade é fruto dela. O filósofo sustenta que todo pensamento original é produzido a partir de imagens. Neste sentido, a fantasia torna-se um instrumento essencial para o gênio. O autor assevera:

Todo pensamento original é produzido a partir de imagens; por isso a fantasia é um instrumento tão necessário para ele, e as mentes sem fantasia nunca irão produzir nada de importante, a não ser no campo das matemáticas. (SCHOPENHAUER, 1958, p. 72).

O núcleo da fantasia é a intuição. É por esse motivo que o gênio, a partir das imagens, consegue produzir algo de novo - nele o conhecimento intuitivo é preponderante. Porém, os meros pensamentos abstratos, que carecem do núcleo intuitivo, não produzem nada de novo. Nas palavras de Schopenhauer, esses pensamentos são "formações nebulosas sem realidade". (SCHOPENHAUER, 1958, p. 72).

Segundo Schopenhauer, todo pensamento é uma combinação de conceitos abstratos. Ele tem como matéria o sumo das lembranças de tudo aquilo que foi previamente intuído. Tudo que é intuído constitui a base de todos os conceitos. Para o filósofo, a base do verdadeiro conhecimento repousa na intuição. Esta é imediata, ou seja, é sempre uma percepção fresca e nova. Os conceitos nunca poderão ocupar a consciência de uma única vez, pois o material captado pela intuição é muito vasto. $\mathrm{O}$ presente intuído pelo entendimento consegue captar a um só golpe o essencial de todas as coisas em geral. Diante disso, a razão sempre estará em desvantagem em relação a esse processo, já que não consegue transformar tudo que fora intuído em conceitos para a consciência.

De acordo com o filósofo, a filosofia e a poesia tentam enriquecer os conceitos a partir da intuição. Entretanto, os livros não podem substituir a experiência e nem a erudição pode substituir o gênio, ou seja, o abstrato - aquilo que se dá por meio de conceitos - nunca poderá substituir o intuitivo - aquilo que se dá através dos sentidos e do intelecto. O conhecimento do gênio consiste em captar as ideias das coisas - ideias no sentindo platônico. Por esse motivo, a erudição não é suficiente para ele: ela oferece meros conceitos. Assim, afirma 
Schopenhauer: "Sabedoria e gênio, os dois picos do Parnaso do conhecimento humano, não repousam em uma faculdade abstrata e discursiva, mas intuitiva. A verdadeira sabedoria é algo intuitivo, e não abstrato". (SCHOPENHAUER, 1958, p. 75).

O conhecimento intuitivo do entendimento é capaz de conduzir, de forma imediata, o agir e a conduta. Todavia, o conhecimento abstrato da razão só pode fazê-lo por intermédio da memória. Com isso, é possível notar a vantagem que o conhecimento intuitivo possui em relação ao conhecimento abstrato. Quando não há espaço para reflexões, o conhecimento intuitivo atua de modo prático - sem o uso de conceitos. Segundo Schopenhauer, na prática o conhecimento intuitivo se mostra muito mais eficaz do que o conhecimento abstrato. Neste sentido, é que se pode explicar porque o erudito - possuidor de um amplo conhecimento abstrato - está em desvantagem em relação ao homem do mundo, cuja vantagem consiste num completo conhecimento intuitivo, fruto de sua disposição originária. Conforme o filósofo, o homem do mundo, cujo conhecimento intuitivo é completo, desenvolve uma rica experiência perante tudo aquilo que lhe ocorre. Sendo assim, ele adquire uma perspicácia muito maior no que concerne às relações humanas do que o homem erudito.

O conhecimento intuitivo é aquele que proporciona a verdadeira compreensão (Einsicht) das coisas. É um conhecimento incondicionalmente verdadeiro. E é nessa perspectiva que Schopenhauer afirma que a virtude tem sua origem no conhecimento intuitivo: todas as ações que são imediatamente suscitadas por ele - como um impulso puro da própria natureza - correspondem ao verdadeiro e imutável caráter. As reflexões e os dogmas, oriundos do conhecimento abstrato, em nada podem contribuir para que sejam produzidas ações virtuosas. A verdadeira concepção de vida, a correta visão e o verdadeiro julgamento nascem do modo como o homem apreende o mundo intuitivo - sem a atuação dos conceitos abstratos.

Para Schopenhauer, podemos encontrar homens que são carentes de cultura e superiores intelectualmente. "Pois o entendimento natural pode suprir quase qualquer nível de educação, mas nenhuma instrução pode substituir o entendimento natural". (SCHOPENHAUER, 1958, p. 77). Em relação ao homem inculto, o erudito possui uma vantagem no que se refere ao conhecimento histórico e à teoria da natureza. No entanto, o homem inculto, de visão aguçada - concedida pelo entendimento puro - consegue viver sem todos esses conhecimentos. De acordo com Schopenhauer, o inculto, pela própria experiência, consegue compreender muitas coisas com mais eficácia do que um erudito - $\mathrm{O}$ erudito conhece, mas não compreende verdadeiramente. Schopenhauer afirma: 


\begin{abstract}
Portanto, enquanto para alguns homens incultos a correta compreensão intuitiva do mundo foi impressa na fronte como um selo de sabedoria, o rosto de alguns eruditos leva os traços do esgotamento e do desgaste dos seus numerosos estudos, devido ao trabalho forçado e o uso excessivo da memória, de forma antinatural, para acumular conceitos mortos: esse sujeito parece tão simples, tolo e tímido, para não supor que o excessivo esforço da força cognoscitiva mediata, aplicada ao abstrato, produz um enfraquecimento direto da imediata e intuitiva, e que a visão correta natural é cada vez mais substituida pela luz dos livros. (SCHOPENHAUER, 1958, p. 78).
\end{abstract}

Sob o olhar do autor de $O$ Mundo, podemos notar uma espécie de hierarquia entre os homens, principalmente no que diz respeito à atuação do conhecimento intuitivo. Para ele, há uma espécie de predisposição natural que torna alguns homens mais intuitivamente arguciosos do que outros. Por esse motivo, o excessivo esforço do erudito para conseguir acumular conceitos em sua memória não consegue fazer com que este produza algo novo. Os conceitos abstratos, acumulados pelo erudito não podem substituir aquilo que fora captado pela intuição. Esta produz um conhecimento imediato, autêntico e novo. O erudito tenta, sem sucesso - através do conhecimento mediato da razão - produzir algo de original. Em síntese, nenhum conhecimento abstrato (mediato), produzido pela razão, pode substituir o conhecimento intuitivo (imediato) produzido pelo entendimento. Schopenhauer afirma:

\begin{abstract}
A grande utilidade dos conceitos consiste no fato de que, por meio deles, se pode facilmente ter à mão, abarcar e ordenar a matéria original do conhecimento: através das muitas operações lógicas e dialética que é possível realizar com eles, mas nunca surgirá daí um conhecimento novo e original. (SCHOPENHAUER, 1958, p. 82).
\end{abstract}

Conforme Schopenhauer, o material de trabalho da filosofia é a consciência empírica, que se decompõe na consciência do próprio eu (autoconsciência) e na consciência que se tem das outras coisas (intuição externa). Para o autor, ela é o único imediato e realmente dado. Deste modo, todas as filosofias que adotam os conceitos abstratos como ponto de partida, na visão de Schopenhauer, se nos apresentam como destituídas de fundamento, pois não se apoiam no solo seguro da intuição. Na concepção de Schopenhauer, os conceitos são os instrumentos de trabalho da filosofia. Não obstante, seguindo um exemplo dado pelo autor, o mármore não pode ser confundido com a escultura. Tudo aquilo que fora captado por meio da intuição deve ser transformado em conceitos, mas sem perder a própria intuição como ponto de partida. O filósofo alega que todas as amplas abstrações abandonam o conhecimento intuitivo, e, por esse motivo, tornam-se uma fonte inesgotável de erros.

Há uma grande diferença entre o conhecimento intuitivo e o conhecimento abstrato ou reflexivo. Schopenhauer afirma que a distinção entre esses dois tipos específicos de conhecimento é umas das características fundamentais de sua filosofia. Pois, segundo ele, muitos fenômenos da nossa vida intelectual só podem ser explicados a partir dela. Como se 
sabe, existe uma faculdade intermediária que une esses dois tipos de conhecimento, a saber: a faculdade de juízo. Essa faculdade atua apenas no campo dos conhecimentos abstratos comparando conceitos com conceitos. Todo juízo - no sentido lógico do termo - é obra da faculdade de juízo. A faculdade de juízo subsume um conceito mais estrito em outro conceito mais amplo.

Essa atividade da faculdade de juízo, em que se comparam conceitos entre si, é inferior e mais fácil do que aquela em que se realiza o trânsito desde o plenamente individual, o intuitivo, ao essencialmente universal, o conceito. Pois aí, através da análises dos conceitos, em seus predicados essenciais, se há de poder decidir sua compatibilidade ou incompatibilidade por uma via puramente lógica, para o qual basta o simples uso da razão que reside em cada sujeito. Assim, o juízo atua abreviando esse processo. O sujeito dotado de juízo consegue ver rapidamente aquilo que outro só consegue extrair por meio de muitas reflexões. A atividade da faculdade de juízo consiste em traduzir todo o material que fora apreendido intuitivamente - imediatamente - subsumindo-o em conceitos exatamente adequados e, por último, depositando-o no saber reflexivo.

Segundo Schopenhauer, a faculdade de juízo é responsável por instaurar os fundamentos sólidos de todas as ciências. Ademais, esses fundamentos são sempre formados por aquilo que fora conhecido intuitivamente e não ulteriormente deduzido. Nos juízos fundamentais, as dificuldades residem neles mesmos, e não nos raciocínios que se dão a partir deles. "Raciocinar é fácil, julgar, difícil". (SCHOPENHAUER, 1958, p. 88). Conforme o filósofo, os falsos raciocínios são extremamente raros. Todavia, os falsos juízos são encontrados diariamente. Quando num juízo tentamos passar da consequência à razão, entramos num caminho inseguro; é aqui que reside a fonte de todo erro. Schopenhauer evidencia: "[...] a grande dificuldade do juízo consiste, na maioria dos casos, em temos que ir da consequencia à razão, esse caminho é sempre incerto, eu tenho mostrado que aqui reside a fonte de todos os erros". (SCHOPENHAUER, 1958, p. 89). Ao produzir os conceitos, a faculdade de razão nos torna "propensos" ao erro (a razão produz a dimensão abstrata do conhecimento). Mas, quem nos faz "cair" no erro é a faculdade de juízo (a faculdade de juízo trabalha com os conceitos da razão) quando compara conceitos com conceitos e quando tenta ir da consequência à razão. Deste modo, as duas faculdades possuem uma parcela de culpa no que concerne à questão do erro.

A partir daí, é necessário ressaltar que tentar "ir da consequência à razão" é o único caminho disponível para as ciências empíricas e para todos os assuntos concernentes à vida 
real. Logo, podemos concluir que todos estão propensos ao erro. As únicas ciências que se nos apresentam como seguras no que tange à passagem da razão à consequência são as ciências objetivas, a saber: a lógica e a matemática, que são ciências a priori. (Cf. SCHOPENHAUER, 1958, p. 89). Elas se baseiam nas formas subjetivas do intelecto, ou seja, suas verdades estão de acordo com todos aqueles que as entendem.

$\mathrm{Na}$ perspectiva de Schopenhauer, a inteligência e a sagacidade são manifestações da faculdade de juízo. Na inteligência, a faculdade de juízo atua reflexionando - passando corretamente da razão à consequência. Já na sagacidade, a faculdade de juízo atua subsumindo - inserindo um conceito mais estrito em um conceito mais amplo. Para o filósofo, o homem vulgar não possui confiança no seu próprio juízo - mesmo quando se trata de assuntos simples. Além disso, este tipo específico de homem se apega aos juízos de segunda mão (Nachurteil), isto é, se apoia nos juízos de outrem. Por esse motivo, ele permanece sempre na menoridade, em outras palavras, na incapacidade de julgar por si mesmo. Neste caso, o que conta para ele é a opinião dos outros. A rápida difusão dos erros provém dessa incapacidade de julgar por si mesmo. Esta, segundo Schopenhauer, é uma característica comum a quase todos os homens. Desta forma, o erro, no âmbito do juízo, é sempre retransmitido.

\section{5 - Conclusão}

Para fundamentar a sua metafísica da Vontade, Schopenhauer altera o modo de operação da faculdade de razão. O filósofo apresenta uma divisão entre conhecimento intuitivo (as representações intuitivas) e conhecimento abstrato (as representações abstratas). Por causa dessa divisão, a razão acaba saindo empobrecida. Em síntese, a faculdade de razão passa a responder por aspectos meramente lógicos no que concerne ao processo de construção do conhecimento. À diferença do transcendentalismo kantiano, que considera a faculdade de razão como responsável pela produção dos conceitos puros e das ideias transcendentais, Schopenhauer oferece uma razão com uma única função, a saber: a capacidade de produzir conceitos abstratos. Contudo, na visão do autor de $O$ Mundo, a razão aparece com uma faculdade essencialmente dependente do entendimento. Aqui, é o entendimento que oferece as regras para a atuação da razão. Como se sabe, o entendimento (através de sua categoria da causalidade) unido às formas puras do espaço e do tempo produz as representações intuitivas. Segundo o filósofo, a faculdade de razão desenvolve as suas esferas conceituais a partir destas representações. 
Os conceitos produzidos pela razão devem sempre se referir à dimensão intuitiva do conhecimento. Para o filósofo, quando a razão deixa de observar essa regra fundamental, ela passa a produzir conceitos vazios de conteúdo, ou seja, conceitos sem referência empírica. Por exemplo: Deus, alma, substância etc. Essa superioridade do conhecimento intuitivo em relação ao conhecimento abstrato perpassa todas as obras de Schopenhauer. $\mathrm{Na}$ filosofia schopenhaueriana, essa superioridade é apresentada, com muita clareza, na estética, na ética e na metafísica. É no campo da representação que Schopenhauer desenvolve a imagem de uma razão a serviço dos impulsos imperativos da vida. Com isso, a razão perde toda posição de destaque, no que tange à construção do conhecimento, que gozava nos sistemas racionalistas.

\section{REFERÊNCIAS BIBLIOGRÁFICAS}

BARBOZA, Jair. Os limites da expressão. Linguagem e realidade em Schopenhauer. Porto Alegre: Veritas, 2005.

CACCIOLA, Maria Lúcia Mello e Oliveira. Schopenhauer e a questão do dogmatismo. São Paulo: Edusp, 1997.

. Schopenhauer e a crítica da razão: a razão e as representações abstratas. São Paulo: Edusp, 1982.

O intuitivo e o abstrato na filosofia de Schopenhauer. In Schopenhauer e o

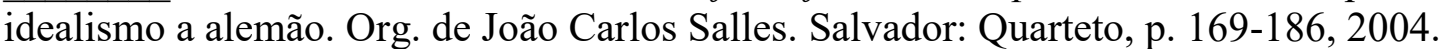

PERNIN, Marie-José. Schopenhauer decifrando o enigma do mundo. Trad. Lucy Magalhães. Rio de Janeiro: Jorge Zahar, 1995.

SCHOPENHUAER, Arthur. De la cuadruple raíz del principio de razón suficiente. Trad. Leopoldo Eulogio Palacios. Madrid: Editorial Gredos, 1981.

. Die Welt als Wille und Vorstellung. Müchen: Bei Georg Muller, 1982.

Unesp, 2005.

O mundo como vontade e como representação. Trad. J. Barboza. São Paulo:

. The world as will and representation, in two volumes: volume II. Trad. E. F. J. Payne. New York: Dover, 1958.

. Sobre a visão e as Cores. Trad. Erlon José Pascoal. São Paulo: Nova Alexandria, 2003. 